\title{
MOD - E \\ MÓdULO ECOLÓGICO RECOLECTOR DE AGUA AMBIENTE
}

Quarin, Aylen Nerea (arquitecta) aylquarin@gmail.com

Sinkovich Naiara Antonella (arquitecta) antosinkovich@hotmail.com

Spath, Tomas (estudiante arquitectura) tomasspath@amail.com

Trabajo Final del Seminario "Biomimética y Proyecto Sostenible". FAU - UNNE. Resistencia, Chaco, República Argentina.

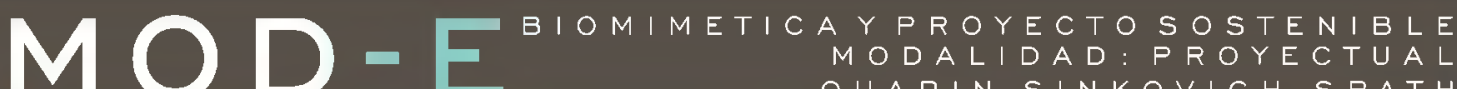 \\ MODALIDAD: PROYECTUA
$Q U A R I N-S I N K O V I C H-S P A T H$}

MÓDULO ECOLÓGICO RECICLADO DE BOTELLAS DE ALUMINIO, QUE LOGRA LA CAPTACIÓN Y POSTERIOR RECOLECCIÓN DE AGUA POR MEDIO DE FENOMENOS NATURALES.

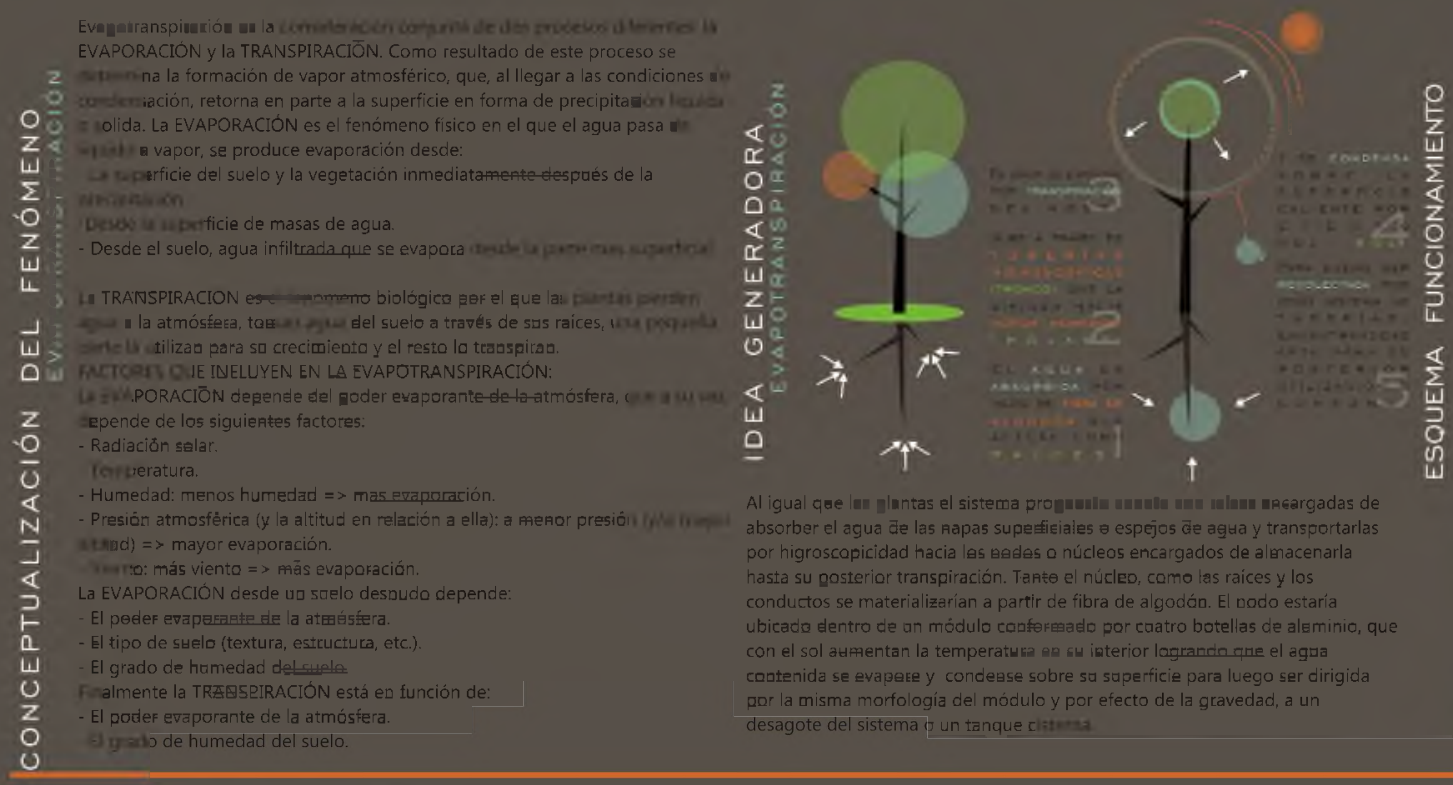

MODULO ECOLÓGICO RECOLECTOR DEAGUAAMBIENTE 


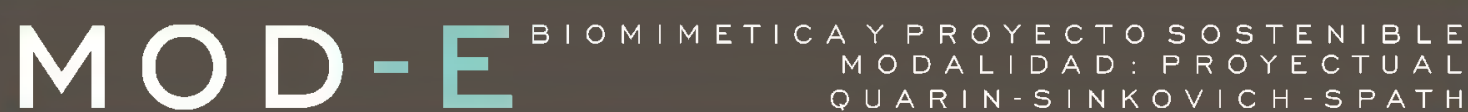

MÓDULO ECOLÓGICO RECICLADO DE BOTELLAS DE ALUMINIO, QUE LOGRA LA CAPTACIÓN Y POSTERIOR RECOLECCIÓN DE AGUA POR MEDIO DE FENÓMENOS NATURALES.

A partir de la unión de 4 botellas de aluminio logramos el módulo que contendrimiento.

OBJETIVO:

Obtener agua de manera sencilla por medio de un elemento

reciclado, cuya instalación aproveche la energía solar y la humedac del medio.

ALBERGA 3 SISTEMAS:

-estructural

-absorción

-recolecció
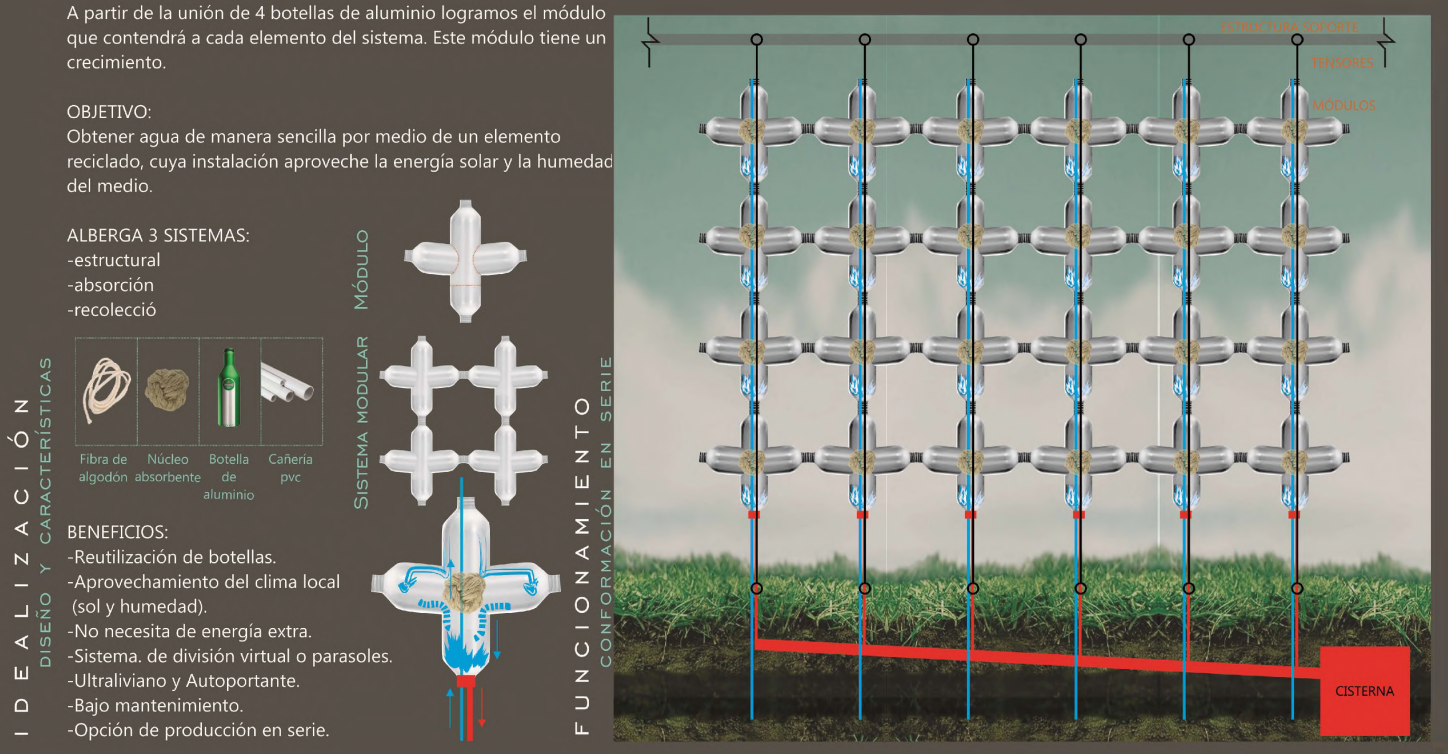

MÓ DULO ECOLÓGICO RECOLECTOR DE A G U A A M B I E N T E

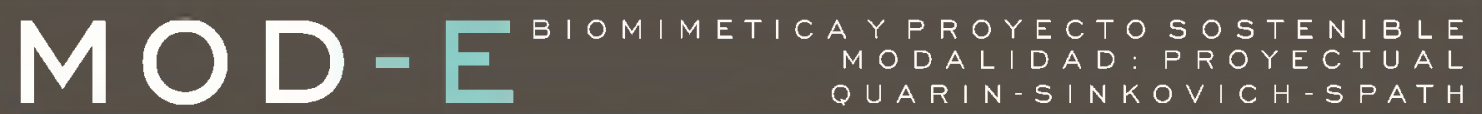

MÓDULO ECOLÓGICO RECICLADO DE BOTELLAS DE ALUMINIO, QUE LOGRA LA CAPTACIÓN Y POSTERIOR RECOLECCIÓN DE AGUA POR MEDIO DE FENÓMENOS NATURALES.

ESQUEMA DE IMPLEMENTACIÓN
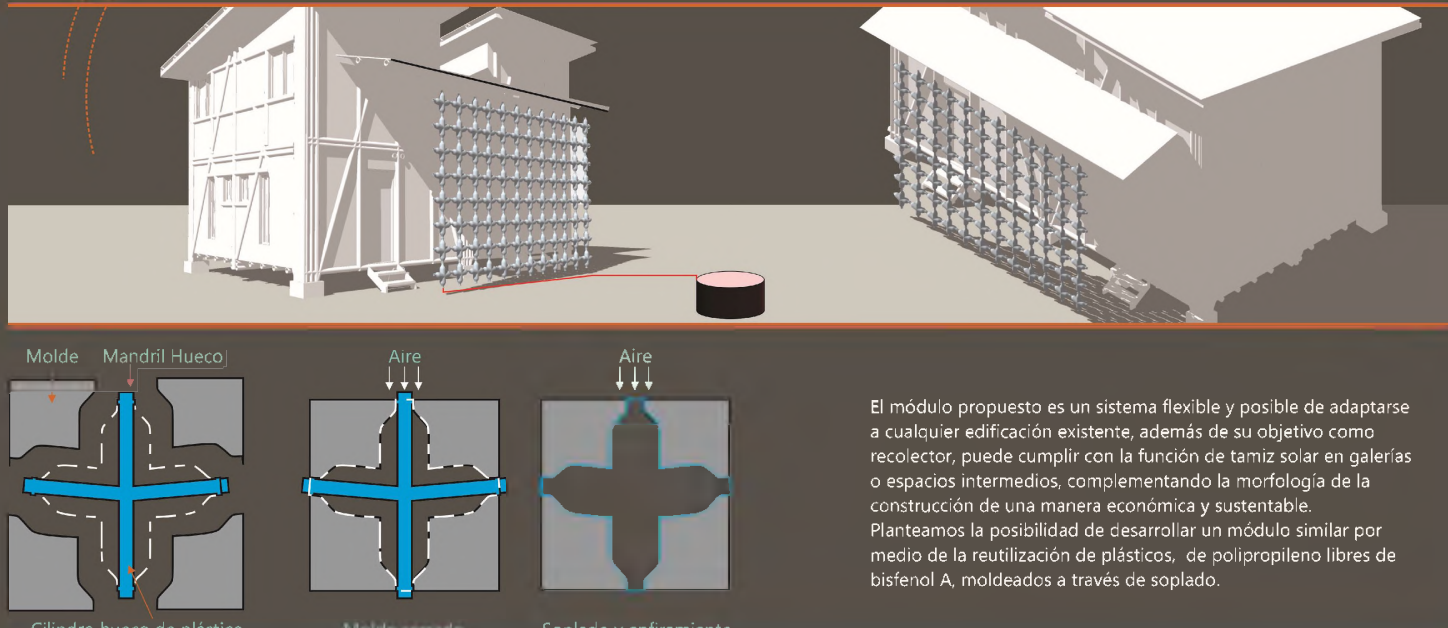

El módulo propuesto es un sistema flexible y posible de adaptarse a cualquier edificación existente, además de su objetivo como recolector, puede cumplir con la función de tamiz solar en galerías o espacios intermedios, complementando la morfología de la construcción de una manera económica y sustentable

Planteamos la posibilidad de desarrollar un módulo similar por medio de la reutilización de plásticos, de polipropileno libres de bisfenol $A$, moldeados a través de soplado.

\footnotetext{
MODULOECOLÓGICO RECOLECTOR DEA A G A A M B I E T T E
} 